\title{
THE EFFECT OF LUBRICATION ON THE VIBRATION OF ROLLER BEARINGS
}

\author{
N.F.M. Yusof* and Z.M. Ripin \\ School of Mechanical Engineering \\ Universiti Sains Malaysia \\ *Email: mefarhana@usm.my
}

\begin{abstract}
Proper lubrication is crucial to ensure smooth operation in machineries. In rolling bearing, the improper lubrication may induce high friction and vibration level due to metal to metal contact between the rolling elements. In this study, the roller bearings with and without lubrication are investigated. The natural surface degradation of the roller bearing is monitored and the surface roughness is measured for the lubricant film thickness calculation. The film thickness is determined by the HamrockDowson equation which showed that the grease lubricated bearing operated under the elastro-hydrodynamic lubrication, with the ratio of lubrication film thickness to the surface roughness of $\lambda$ in the range of 0.9 to 3.65. The un-lubricated bearing was damaged after 20 minutes whereas the grease lubricated bearing continued to operate for 6600 minutes. The observation under microscope showed that the surface underwent smoothening process where the surface roughness decreases initially (running-in state) followed by roughening at the steady state where the surface roughness increases. At damage, the value of $\lambda=0.9$ can be associated with the high level of the bearing vibration. The increase of vibration level becomes rapid at the critical value of $\lambda=1.6$. As such the overall vibration level of the bearing can be related to the surface degradation and low film thickness.
\end{abstract}

Keywords: Roller bearing, vibration, surface roughness

\section{INTRODUCTION}

Rolling element bearings have widespread applications particularly in industrial machineries. These bearings are considered as critical mechanical components in industrial applications and the failure to detect the presence of defects may lead to catastrophic failure of the machinery. The condition monitoring of the rolling bearing is commonly carried out by vibration measurement. The rolling element bearing produces noise and vibration because of the sliding or rolling contact of the bearing components [1]. Additional factors influencing the noise and vibration include manufacturing inaccuracies, improper installation, operating speed, supported load and lubricant [2]. The trend of vibration acceleration shows sudden increase and decrease during the early cycle (running-in) of rolling contact [3]. The fluctuation of the signal level was attributed to phenomenon known as healing which is described as smoothing of sharp edge of surface asperities by continuing rolling contact $[3,4]$.

Lubrication plays an important role in order to ensure a smooth bearing operating condition. The function of lubrication is to form a layer of a different material between the surfaces that reduce the friction force between them. FAG Technical 
Publication [5] stated that $80 \%$ of bearing failures are caused by lubricant failure. The changes in lubrication condition of rolling bearing mainly affect its vibration in high frequency band $[6,7]$. The vibration level increases with the decrement of the minimum film thickness and lambda value [8]. The higher vibration level was excited with the increase of grease base viscosity [9]. Improper lubrication can be expressed by the increase in the spectral components at bearing cage and ball spin frequency [10]. The full film lubrication (hydrodynamic lubrication) cannot be reached under certain operating conditions such as low speed, very high load, and at very high temperature as a thin and inadequately separating lubricating film is formed [11]. The boundary between fully flooded and starved regime is determined by volume, contact dimensions, oil viscosity and speed [12]. In grease-lubricated contacts, a fully flooded condition occur initially then shift to starved condition in a short time $[13,14]$. The mechanical aging process reduces the thickener material subsequently decrease the grease film thickness at very low speeds, however no significant difference was found at higher speeds where the grease film thickness still approached the calculated base oil film thickness [15]. In this study, vibration level and lubrication condition of the grease lubricated bearing will be monitored until failure. The lubricant film thickness is calculated by using surface roughness value.

\section{METHODOLOGY}

\section{Experimental Setup}

A detachable roller bearing is selected for this study which is the NU205E.TVP2.C3 cylindrical roller bearing made from chrome steel. The roller bearing is designed to permit relative motion between two machine parts, usually between a rotating shaft and a fixed frame supporting the applied load. The load placed on the bearing is supported by the contact surface between the inner raceway and the rollers. The geometry of the bearing is shown in Table 1 .

Table 1. Roller bearing geometry

\begin{tabular}{|c|c|c|c|c|}
\hline \multirow[b]{2}{*}{ A } & \multirow{5}{*}{$\hat{T} \int_{i}{ }_{d_{n}}$} & \multirow{2}{*}{4} & Number of roller & 13 \\
\hline & & & Roller diameter (dr) & $7.5 \mathrm{~mm}$ \\
\hline & & \multirow{2}{*}{$D_{0}$} & Inner bore diameter $(\mathrm{Di})$ & $25 \mathrm{~mm}$ \\
\hline \multirow{4}{*}{ 夏 } & & & Outer ring outside diameter (Do) & $52 \mathrm{~mm}$ \\
\hline & & $D_{0}$ & Pitch diameter $(\mathrm{dm})$ & $38.5 \mathrm{~mm}$ \\
\hline & \multirow{2}{*}{$\downarrow$} & & Width (B) & $15 \mathrm{~mm}$ \\
\hline & & & Weight & $0.14 \mathrm{~kg}$ \\
\hline
\end{tabular}

A rotation system is designed and fabricated for this study. Figure 1 shows the experiment test rig which consists of bearings, motor, load, shaft coupling, speed controller and data acquisition system. The shaft is supported by two pillow blocks. The test bearing is fitted to one end of the shaft. During operation, the bearing inner ring rotated with the shaft while the outer ring remained stationary. The steel shaft is driven by an $\mathrm{AC}$ motor (Marelli Motor) and the speed controlled by speed controller 
(Emerson). The shaft speed was set to $1500 \mathrm{rpm}(25 \mathrm{~Hz})$. The rotational speed of the shaft is measured using laser tachometer (Optel-Thevon). A load of $900 \mathrm{~N}$ is applied.

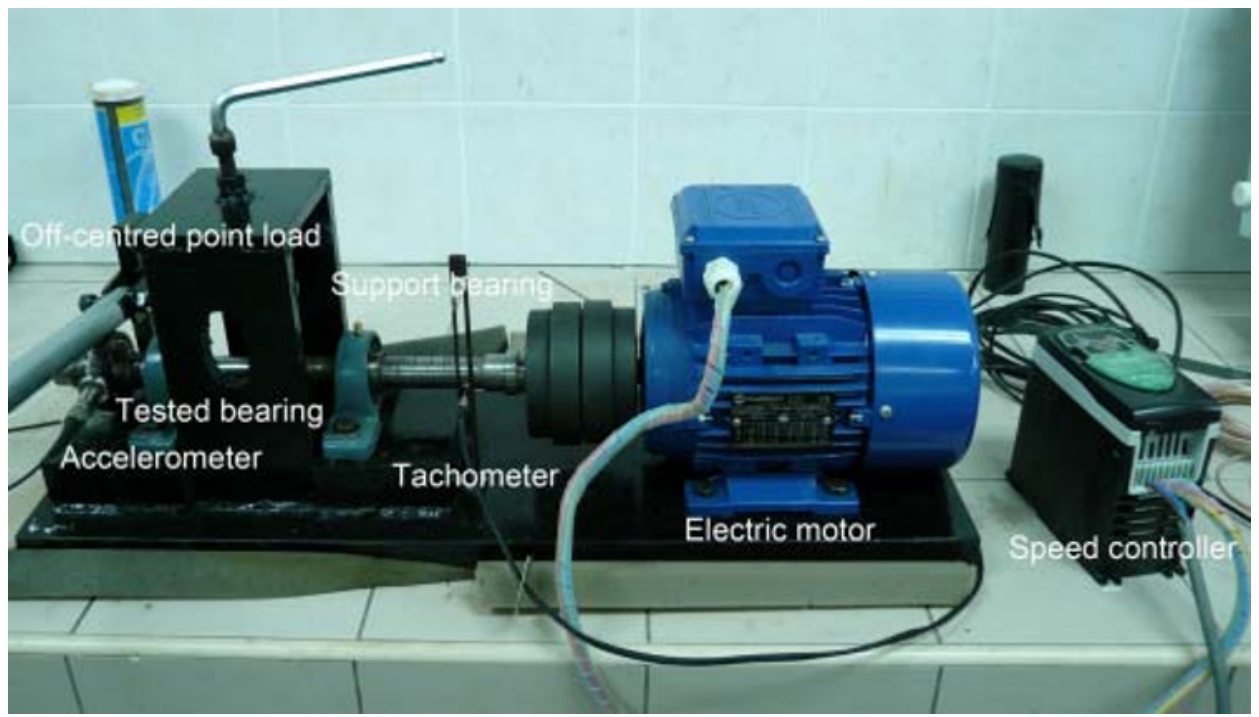

Figure 1. Experimental test rig

\section{Vibration Measurement}

The vibration level of roller bearings is measured by using accelerometer (DYTRAN) that is mounted horizontally on the bearing housing. The accelerometer calibration is performed at the beginning of the measurement. The shaft speed is monitored by tachometer probe. The signals from accelerometer and tachometer are processed with LMS Test.Xpress software and hardware with the sampling rate set at 5 $\mathrm{kHz}$. The vibration data is analyzed in term of root mean square (RMS) value.

\section{Lubricant Film Thickness Measurement}

The bearings are tested for un-lubricated and lubricated conditions. For unlubricated condition, the whole bearing is cleaned and submerged in ethanol for one hour. The intention is to remove all trace of lubricant for the bearing in the un-lubricated condition. For lubricated test, the SKF LGMT 20.4 grease is used in the experiment. The mineral base oil with Lithium thickener grease with viscosity of $110 \mathrm{~mm}^{2} / \mathrm{s}$ at $40{ }^{\circ} \mathrm{C}$ and $100{ }^{\circ} \mathrm{C}$ at $11 \mathrm{~mm}^{2} / \mathrm{s}$ is used. Surface roughness measurement is performed periodically in order to measure surface roughness for film thickness and lambda calculation. In order to do that, the lubricated bearing is removed every 30 minutes and cleaned for the characterization. For un-lubricated bearing, the bearing is removed more frequently as early damaged is expected. After characterization, the bearing is relubricated and remounted. The surface characterization is performed by using Infinite Focus Microscopy (IFM).

The lubrication condition is determined through minimum film thickness between the inner race and roller which present tribological contact in rolling bearing. The minimum film thickness, $\mathrm{h}_{\min }$ for roller bearing is calculated using HamrockDowson equation [16]; 


$$
\mathrm{h}_{\min }=3.63 \mathrm{U}^{0.68} \mathrm{G}^{0.49} \mathrm{~W}^{-0.073}
$$

where $h_{\min }$ is the min film thickness, $U$ is speed parameter, $G$ is material parameter and $\mathrm{W}$ is load parameter.

The relation between roughness and film thickness is defined by $\lambda$ parameter as shown below [16], and can be used as an indicator of the lubrication regime.

$$
\lambda=/ \frac{\operatorname{hming}}{\sqrt{R_{\text {ga }}^{2}+R_{\text {ga }}^{\mathrm{N}}}}
$$

where $\mathrm{R}_{\mathrm{q}}$ is a root mean square roughness height of two contact surfaces.

\section{RESULTS AND DISCUSSIONS}

The un-lubricated roller bearing shows signs of failure during the early stage of the experiment which produces noise and this gradually become worse until unacceptable noise and vibration level produced after 20 minutes. For the lubricated bearing it was considered damaged after producing high noise level after 110 hours (6600 minutes) of operation. The average roughness $\left(\mathrm{R}_{\mathrm{a}}\right)$ measurement shows that the value is decrease initially as shown in Figure 2. Similar trend was also observed by [4, 17] where during this period, the continuous rolling contact between the roller and inner raceway causes plastic deformation for the two contacting surface asperities and reduces the roughness which is also known as polishing effect. For the un-lubricated bearing, the asperities polishing only took place for two minutes. It was explained that in the operation where an inadequate lubrication applied, the minimum film thickness is lower than surface asperities. Under un-lubricated condition where the severity of operation is increased, there is no lubrication film to support the load. The value started to increase after 7 minutes and 90 minutes for un-lubricated and lubricated condition respectively where the surface roughening took place until the bearing failure.

The minimum film thickness $\left(\mathrm{h}_{\min }\right)$ calculated by using Hamrock- Dowson equation [16] is obtained at $0.36 \mu \mathrm{m}$. The relation between roughness and film thickness, $(\lambda)$ is calculated to identify the lubrication regime of bearing running under grease lubrication. The assumption is that, the $h_{\min }$ is constant throughout the operation but the roughness change. The measured roughness during surface characterization is applied in the equation of measuring $\lambda$. The lubrication regime indicated by $\lambda$ as function of time is shown in Figure 3. The figure shows that most of the time the bearing is operating in partial elasto-hydrodynamic (EHL) regime. The full film EHL regime is only achieved at the start of experiment. At the final of experiment, which at the period when the bearing shows a sign of failure, the boundary lubrication is reached.

In order to investigate the correlation between vibration and tribological phenomena, a vibration data for lubricated bearing are plotted against the $\lambda$ parameter as shown in Figure 4. The low level of vibration is detected for lambda above 1.8 and unacceptable high level of vibration at lambda of 1.6 with growing level of intermediate value. Previous study [8] showed that for fully flooded lubrication, a $\lambda=12$ can be achieved initially and even for this lubrication indicated that vibration level started to increase when $\lambda<6$. Such results were based on calculated film thickness value of constant $\mathrm{R}_{\mathrm{a}}$. The results shown in figure 4 is important since the vibration value at the 
bearing clearly showed dependency on the $\lambda$ value and critical lambda value of $\lambda=1.6$ is the turning point where the vibration level begin to rise.

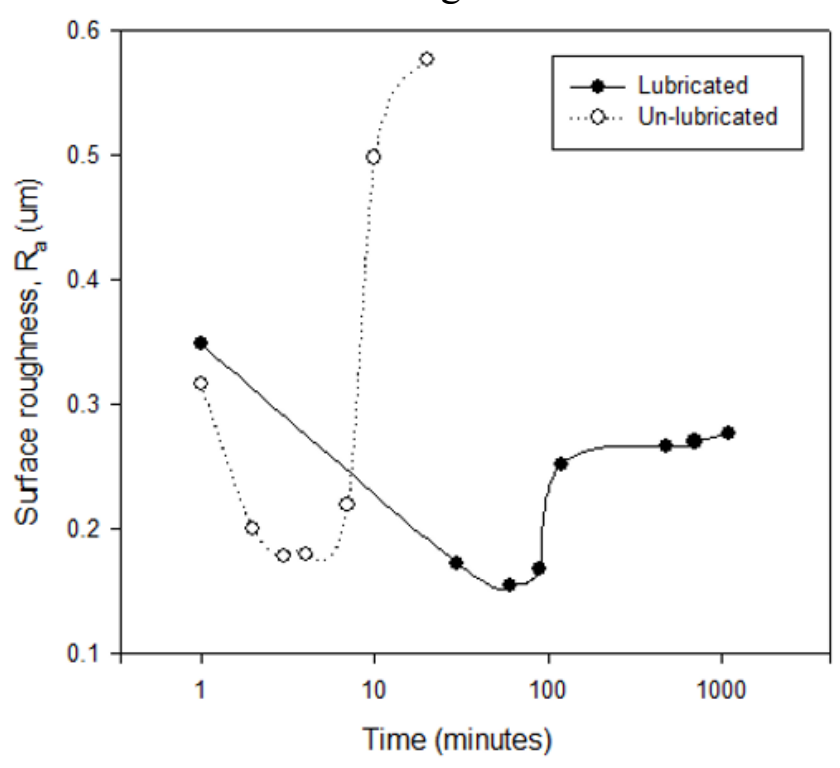

Figure 2 Surface roughness as a function of time

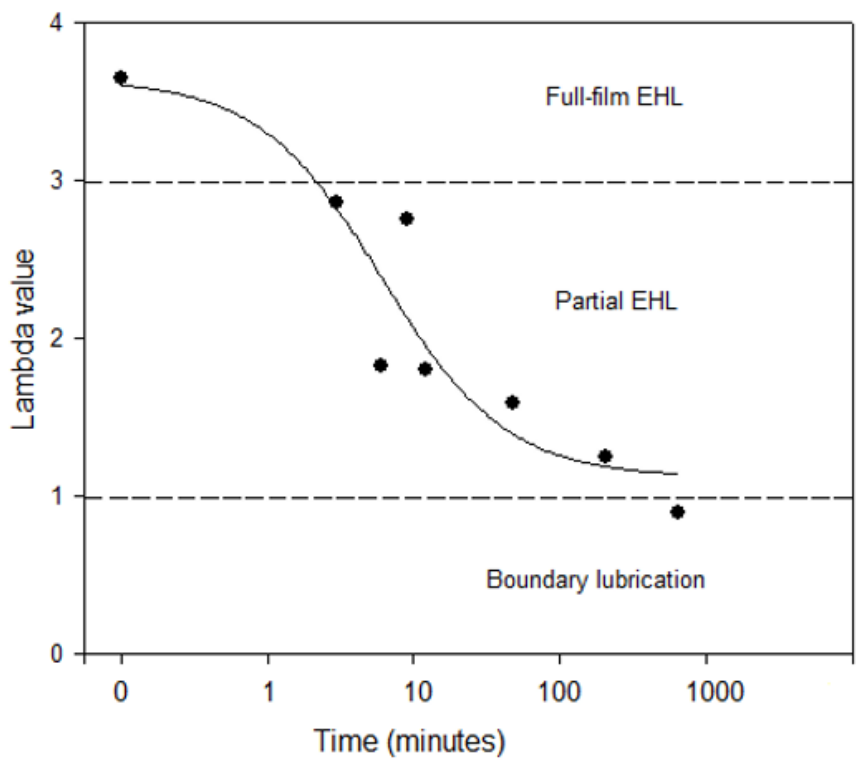

Figure 3. Lambda $\lambda$ value as a function of time 


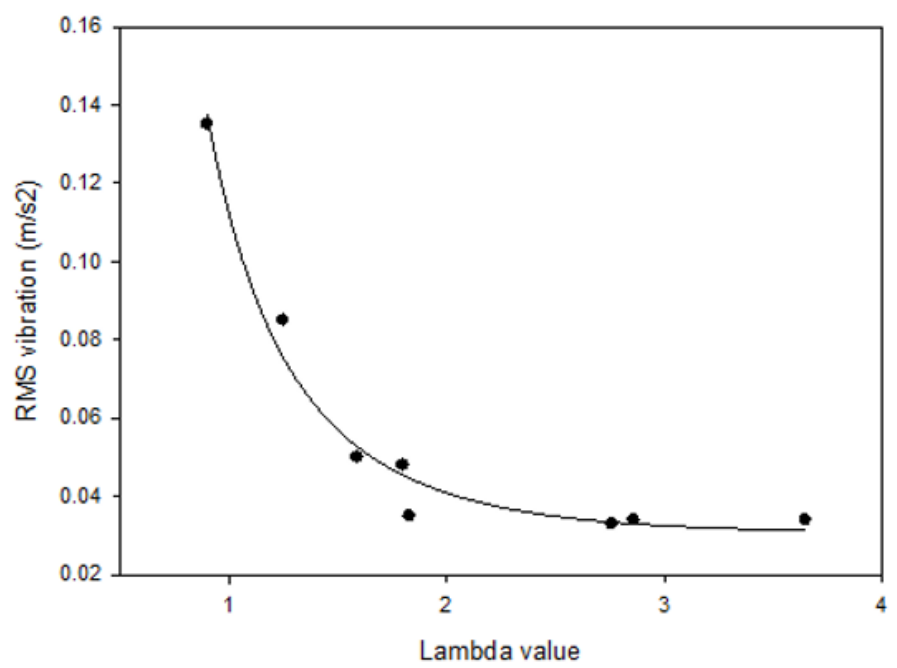

Figure 4 RMS vibration as a function of $\lambda$ (film thickness/roughness)

\section{CONCLUSION}

The conclusions of this study are as follows:

1. The grease lubricated roller bearing has proved to be able to delay the surface degradation and failure. With un-lubricated condition, the surface roughening is accelerated and the vibration level is increased.

2. The lubrication plays an important role to ensure proper roller bearing operation. A high level of the vibration level is indicated at the smaller $\lambda$ where the critical lambda value of $\lambda=1.6$ is the turning point where the vibration level begin to rise.

\section{ACKNOWLEDGEMENTS}

The authors would like to acknowledge Universiti Sains Malaysia for providing the financial assistance under Short-term grant (304/PMEKANIK/60313052).

\section{REFERENCES}

[1] Norton, M. and Karczub, D. (2003). Fundamentals of Noise and Vibration Analysis for Engineers. Second Edition. Cambridge University Press.

[2] Patil, M.S., Mathew, J. and RajendraKumar, P.K. (2008). Bearing Signature Analysis as a Medium for Fault Detection: A Review. Journal of Tribology. 130:1 014001-7.

[3] Williams, T. (2001). Rolling element bearing diagnostics in run-to-failure lifetime testing. Mechanical Systems and Signal Processing. 15:5 979-993. 
[4] Halme, J. and Anderson, P. (2009). Rolling contact fatigue and wear fundamentals for rolling bearing diagnostics. VTT Technical Research Centre of Finland. 224:J: 377393.

[5] FAG Rolling bearing damage: Recognition of damage and bearing inspection. (1996). Publication no. WL 82 102/2 ED.

[6] Maru, M.M., Castillo, R.S. and Padovese, L.R. (2005). Detection of solid contamination in rolling bearing operation through mechanical signature analysis. In: Proceedings of 12th International Congress on Sound and Vibration. Portugal.

[7] Serrato, R., Maru, M.M., Padovese, L.R. (2005). Effect of lubricant oil viscosity and contamination on the mechanical signature of roller bearings. In: Proceedings of 12th International Congress on Sound and Vibration. Portugal.

[8] Serrato, R., Maru, M.M. and Padovese, L.R. (2007). Effect of lubricant viscosity grade on mechanical vibration of roller bearings. Tribology International. 40:8 12701275 .

[9] Wunsch, F. (1992). Noise characteristic of lubricating greases used for anti-friction bearings. NLGI Spokesman 56:16-21.

[10] Boškoski, P., Petrovčič, J., Musizza, B. and Juričić, D. (2010) Detection of lubrication starved bearings in electrical motors by means of vibration analysis, Tribology International. 43:9 1683-1692

[11] Ebert, F.J. (2010). Fundamentals of Design and Technology of Rolling Element Bearings. Chinese Journal of Aeronautics, 23(1):123-136.

[12] Cann, P. M. E., Damiens, B. and Lubrecht, A. A. (2004). The transition between fully flooded and starved regimes in EHL. Tribology International 37: 859-864.

[13] Cann, P. M. E. (1999). Starved grease lubrication of rolling contacts. Tribology Transactions. 42: 867-873.

[14] Vengudusamy, B., Kuhn, M., Rankl, M. and Spallek, R. (2016). Film forming behavior of greases under starved and fully flooded EHL conditions, Tribology Transactions. 59:1 62-71

[15] Cen, H., Lugt, P.M and Morales-Espejel, G. (2014). Film thickness of mechanically worked lubricating grease at very low speeds, Tribology Transactions. 57:6 1066-1071.

[16] Hamrock, B.J., Schmid, S.R. and Jacobson, B.O. (1999). Fundamental of Machine Elements. Ohio. Mc Graw Hill.

[17] Akbarzadeh, S. and Khonsari, M.M. (2011). Experimental and theoretical investigation of running-in. Tribology International. 44:2 92-100 